\title{
NEW SYNCHROTRON INJECTION SEPTUM MAGNET AT THE APS*
}

\author{
M. Jaski, ${ }^{\dagger}$ K. Thompson, C. Doose, J. Humbert, and R. Wright \\ Advanced Photon Source, Argonne National Laboratory, Argonne, IL
}

\begin{abstract}
A new direct-drive, out-of-vacuum synchrotron injection septum magnet has been built at the Advanced Photon Source to replace the existing eddy-currentshielded, in-vacuum magnet. We describe the design, assembly, construction, and measurements.
\end{abstract}

\section{INTRODUCTION}

The key motivation for designing a new synchrotron injection septum magnet at the Advanced Photon Source is to remove the laminated core of the magnet from inside the vacuum chamber. Air trapped in the laminated core makes it difficult to pump down to ultra-high vacuum $\left(10^{-11}\right.$ Torr $)$, and bake-out times of several days are common with the original magnet [1]. A new out-ofvacuum magnet is expected to reduce the bake-out time to much less than a day.

\section{OPERATING PARAMETERS}

The new septum magnet must be able to operate at higher energies than the original because of the higher energies required for free electron laser development [2]. Table 1 gives operating parameters for the septum magnet with a nominal beam energy of $650 \mathrm{MeV}$.

Table 1: Operating Parameters at a $650-\mathrm{MeV}$ Nominal Beam Energy

\begin{tabular}{|l|l|l|}
\hline Parameters & Value & Units \\
\hline Minimum Septum Thickness & $0.194(4.93)$ & $\mathrm{In}(\mathrm{mm})$ \\
\hline Physical Length & $38.50(977.9)$ & $\mathrm{In}(\mathrm{mm})$ \\
\hline Effective Length & $31.56(801.6)$ & $\mathrm{In}(\mathrm{mm})$ \\
\hline Bending Angle & 0.28 & $\mathrm{rad}$ \\
\hline Peak Field & 0.74 & $\mathrm{~T}$ \\
\hline Gap Height & $1.181(30.0)$ & $\mathrm{In}(\mathrm{mm})$ \\
\hline Gap Width & $1.49(37.8)$ & $\mathrm{In}(\mathrm{mm})$ \\
\hline Peak Current & 17,662 & $\mathrm{~A}$ \\
\hline $\begin{array}{l}\text { Pulse Width }(1.5 \mathrm{kHz} 1 / 2 \text { sine } \\
\text { wave })\end{array}$ & 333 & $\mu \mathrm{s}$ \\
\hline Pulse Rate & 2 & $\mathrm{~Hz}$ \\
\hline
\end{tabular}

Higher beam energies may be required in future operations.

\section{GENERAL ASSEMBLY}

The general assembly of the synchrotron injection septum is shown in Fig. 1. The core is stacked with laminations to a radius of curvature of $125 \mathrm{in}$. The laminations are 0.007-in.-thick M22 silicone steel with a C5 coating on both surfaces. The lamination thickness was reduced from 0.014 in., as was used on the in-vacuum

\footnotetext{
* Work supported by U.S. Department of Energy, Office of Basic Energy Sciences under contract number W-31-109-ENG-38.

jaski@aps.anl.gov
}

core, to reduce eddy currents and to lower thermal heating and improve field quality. Laminated end packs with Rogowski surfaces [3] on the end corners of the end poles were used to reduce thermal heating caused by the eddy currents. Two A36 steel tie bars are placed in grooves on the top and bottom of the laminated core and are stitch welded in place to hold the core together, as shown in Fig. 2.

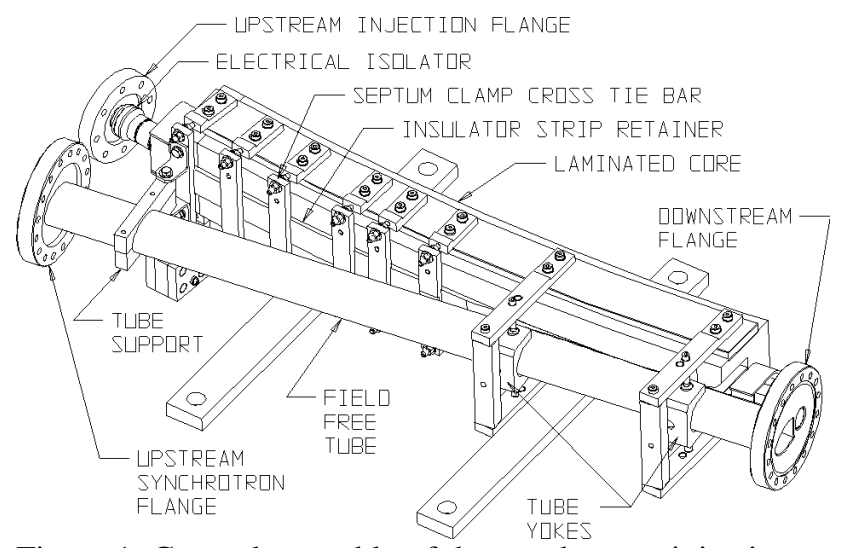

Figure 1: General assembly of the synchrotron injection septum.

Six stainless steel septum clamp cross-tie bars and a stainless steel insulator strip retainer are used to hold the septum in place and to minimize the deflection of the septum during pulses.

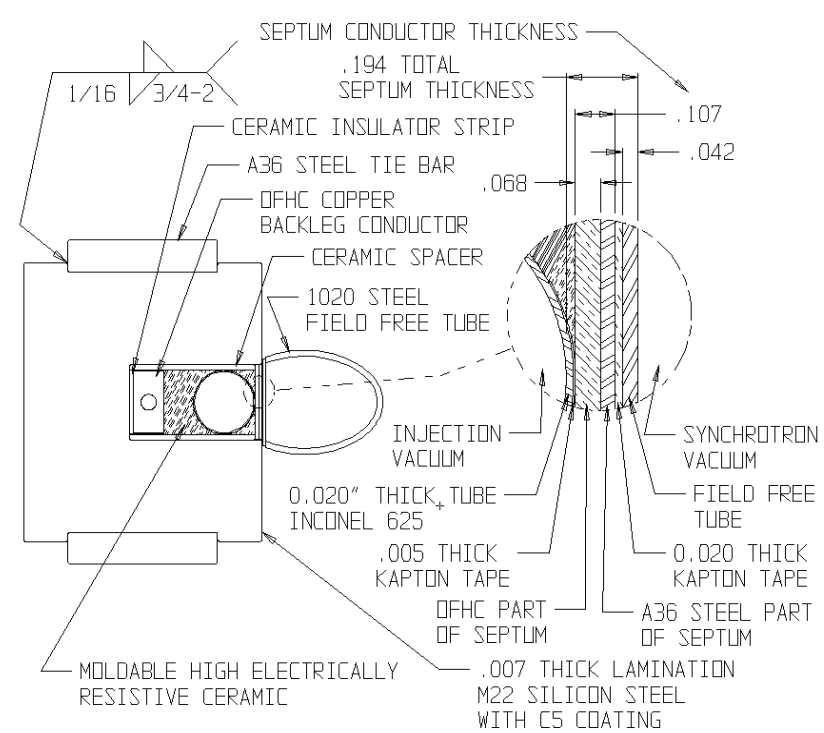

Figure 2: Cross-section of synchrotron injection septum.

A cross-section near the downstream end of the magnet is shown in Fig. 2. The septum conductor is made of oxygen-free, high-conductivity copper, explosive-bonded 
to A36 steel. The backleg conductor, inconel tube, and septum conductor are insulated with ceramic spacers and kapton tape. These parts are potted into the core with a moldable high-electrically-resistive ceramic.

\section{MAGNETIC FIELD ANALYSIS AND MEASUREMENTS}

Nonlinear transient eddy-current electromagnetic field analysis was performed on the synchrotron injection septum magnet using Opera 2D [4]. A two-dimensional plot (position and magnetic field strength at $\mathrm{t}=0.2 \mathrm{~ms}$ ) and three-dimensional plot (time, position, and magnetic field strength) of the main field simulated with Opera 2D is shown in Fig. 3. The analysis is done at 17.98-kA peak current with a one-half sine wave pulse width of $0.4 \mathrm{~ms}$. The average peak field across the entire gap is 7563 gauss with a range that is 7494 gauss (min) near the septum conductor and rises to 7736 gauss (max) near the backleg conductor. The field is uniform over the path of the beam $\left(\mathrm{X}_{1}=0.0\right.$ to 1.1 in.) to 7546 gauss $+/-0.7 \%$.

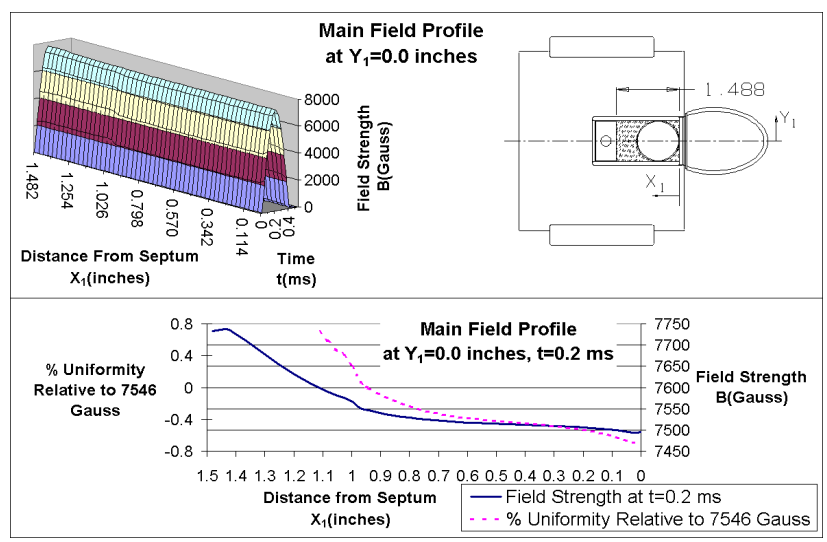

Figure 3: Main field profile.

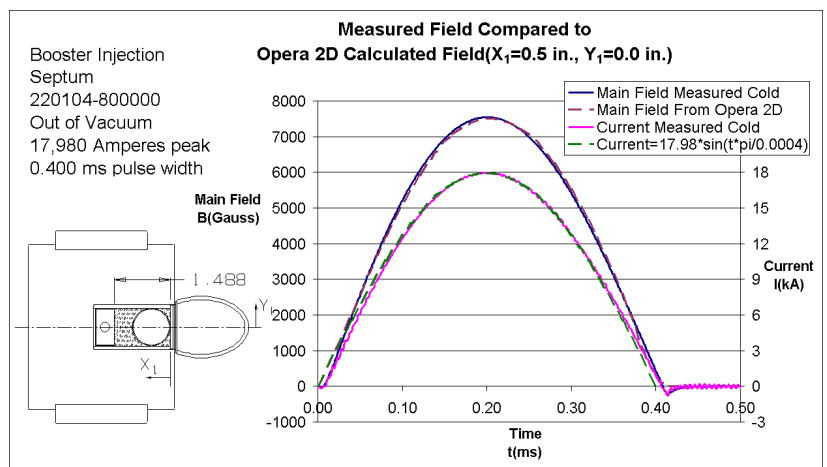

Figure 4: Measured field compared to that calculated by Opera 2D.

Figure 4 shows the plot of the Opera 2D results of the main field at $X_{1}=0.5$ along with the one-half sine pulse current. It also shows a plot of the measured main magnetic field and measured current data. Magnetic field measurements of the main field were taken using a 10turn 10-mm-diameter point coil on a digital oscilloscope. The measured peak value is within $0.4 \%$ of the predicted peak value from Opera 2D.

\section{STRESS/STRAIN ANALYSIS}

Electromagnetic forces on the septum conductor drive the septum away from the core and can be quite large. A formula for approximating the force on the septum conductor is:

$$
\begin{aligned}
& \mathrm{W}=5.71 \times 10^{-7} \mathrm{IB}_{\text {ave }}, \quad \text { where } \mathrm{w}=\frac{\mathrm{lb}}{\mathrm{in}}, \quad \mathrm{I}=\text { amperes } \\
& \mathrm{B}_{\text {ave }}=\frac{\mathrm{B}_{\text {inside_septum }}-\mathrm{B}_{\text {outside_septum }}}{2} \text { gauss. }
\end{aligned}
$$

A static three-dimensional stress/strain analysis, at peak field, was performed on the primary load-supporting parts of the septum magnet using ProlMechanica [5]. Symmetry is used to allow only half of the geometry to be modeled. The analysis was performed at $650 \mathrm{MeV}$ nominal beam energy, which equates to a force of 37.3 lbs/in. along the length of the septum conductor. Fig. 5 shows the stress and displacement results. The maximum Von Mises stress of 14,400 psi in the field-free tube is within the fatigue limit of 1020 steel. The maximum displacement of $0.0031 \mathrm{in}$. in the septum conductor is uncomfortably high. This large displacement will also prevent the septum magnet from performing well at higher energies.

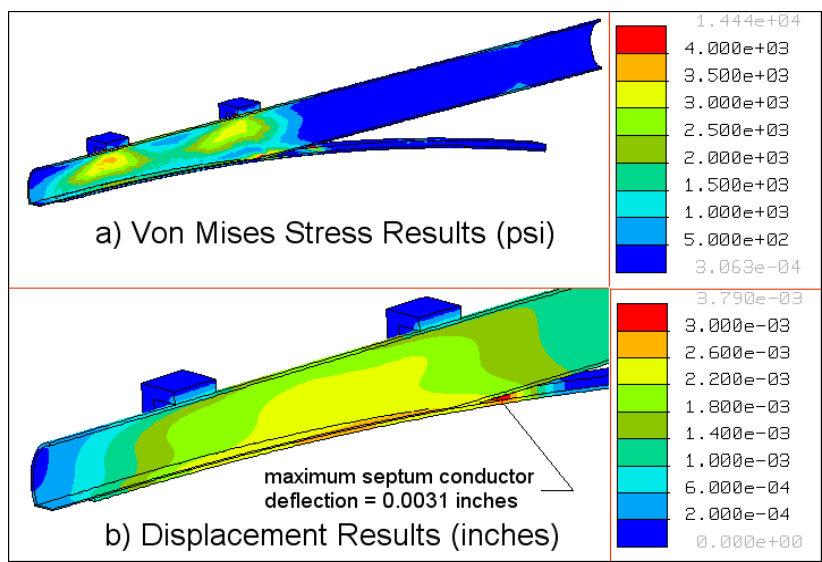

Figure 5: Stress/displacement analysis results for synchrotron injection septum.

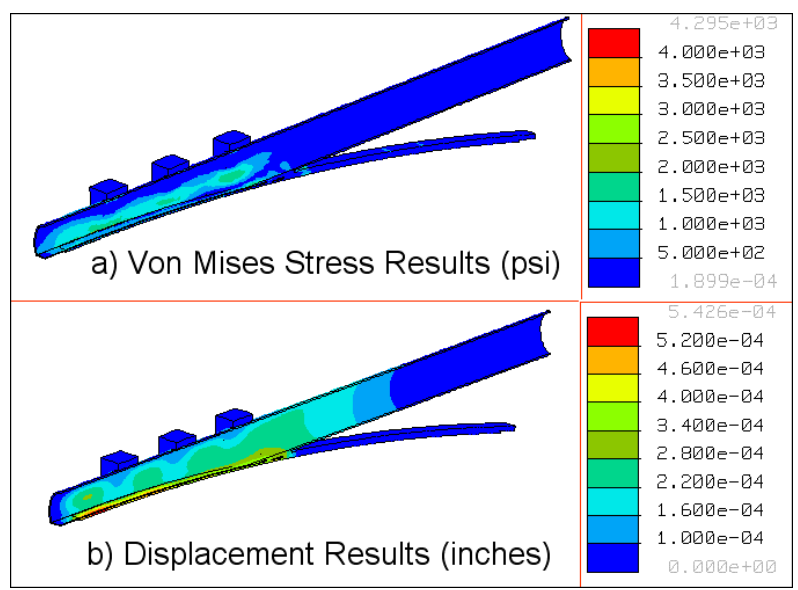

Figure 6: Stress/displacement analysis results for the modified synchrotron injection septum. 
Modifying the tube yokes so they conform to the field free tube's elliptical shape and adding a third tube yoke between the first two yokes reduces the deflection to less than 0.0006 in., as shown in Fig. 6. It also reduces the Von Mises stress in the field-free tube by more than a factor of 3, to 4295 psi. As a result of our analyses, these modifications are now in progress.

\section{THERMAL ANALYSIS}

A two-dimensional steady-state thermal analysis was performed on the septum magnet using ProlMechanica. Symmetry was used, so only half of the model is shown. The analysis was performed at $650-\mathrm{MeV}$ nominal beam energy with a pulse width of $0.4 \mathrm{~ms}$ and a pulse rate of 2 $\mathrm{Hz}$. By integrating the current density over the area of the backleg conductor for several output times in Opera 2D, a plot of the power per unit length versus time can be determined, as shown in Fig. 7. The average power for the backleg conductor can be obtained by dividing the area under the curve by $0.5 \mathrm{~s}$. The average power into the backleg conductor is $7.6 \mathrm{lb}_{\mathrm{f}} / \mathrm{s}$.

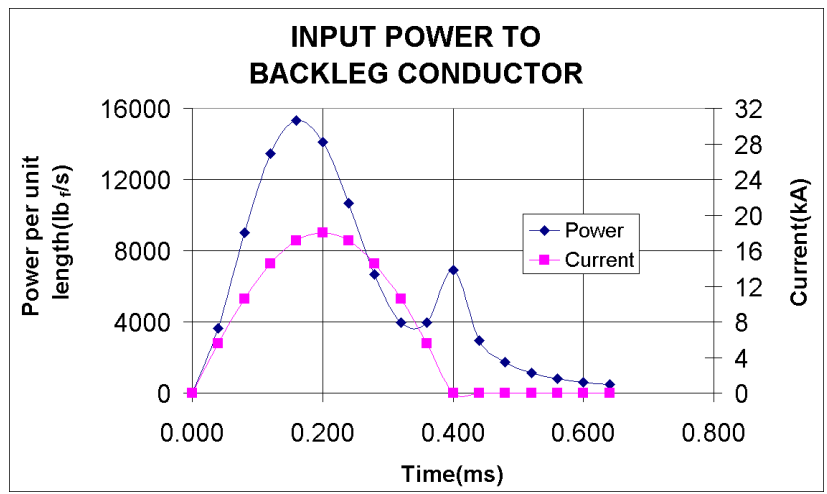

Figure 7: Input power per unit length for the backleg conductor.

Note that the peak power is not synchronized with the peak current. A second peak is also present at $0.4 \mathrm{~ms}$. These phenomena are caused by the presence of eddy currents generated in the backleg conductor.

Table 2: Thermal Heat Loads per Unit Length for the Synchrotron Injection Septum at $650 \mathrm{MeV}$

\begin{tabular}{|l|r|l|}
\hline Backleg conductor & 7.612 & $\mathrm{lb}_{\mathrm{f}} / \mathrm{s}$ \\
\hline Field-free tube & 0.000 & $\mathrm{lb}_{\mathrm{f}} / \mathrm{s}$ \\
\hline Inconel tube & 7.436 & $\mathrm{lb}_{\mathrm{f}} / \mathrm{s}$ \\
\hline Septum copper & 9.684 & $\mathrm{lb}_{\mathrm{f}} / \mathrm{s}$ \\
\hline Septum steel & 0.153 & $\mathrm{lb}_{\mathrm{f}} / \mathrm{s}$ \\
\hline Tie bar & 0.000 & $\mathrm{lb}_{\mathrm{f}} / \mathrm{s}$ \\
\hline
\end{tabular}

Thermal loads can be obtained for the other components in the injection septum by using the same method (see Table 2). Preliminary tests reveal that an average free convection coefficient of $0.027 \mathrm{lb}_{\mathrm{f}} /\left(\mathrm{in}-\mathrm{s}-{ }^{\circ} \mathrm{F}\right)$ can be used for the analysis. Fig. 8 shows the results of the Pro/Mechanica thermal analysis using a bulk temperature of $75^{\circ} \mathrm{F}$. The maximum temperature of $130^{\circ} \mathrm{F}$ is inside the inconel tube closest to the back leg conductor.

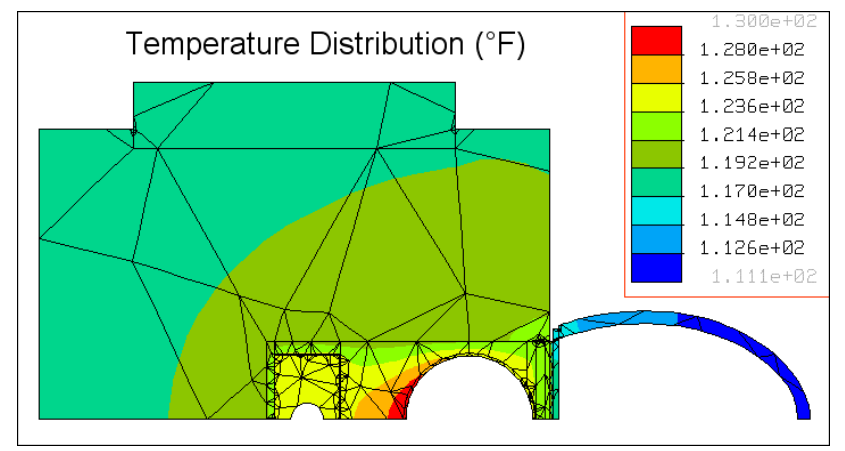

Figure 8: Temperature profile of the synchrotron injection septum at $650 \mathrm{MeV}$.

\section{CONCLUSION}

The first of three synchrotron injection septum magnets has been built and is currently being tested at the Advanced Photon Source. The analyses discussed in this paper show only some of the issues involved in building septum magnets. Other issues that should be taken into account include: safety, sound, thermal expansion, vibration analysis, welding and brazing techniques, fatigue, eddy current heating of the end packs, main field end effects, leakage field, magnetic saturation, effective length measurements, heat-up time, electrical insulation, other types of septum magnets, delaminating issues, cooling, corrosion, radiation effects, and power supply.

\section{ACKNOWLEDGMENTS}

We offer great thanks to Ju Wang and Jeff Goetzen of the power supplies group, who oversaw the power supply during the magnet testing. A special thanks goes to Oliver Schmidt, who made the three-dimensional drawing models of the synchrotron injection septum.

\section{REFERENCES}

[1] A. Gorski, R. Wright, C. Pitts, S. Sharma, "Design and Construction of Septum Magnets at the 7-GeV APS," Proc. 1999 Particle Accelerator Conference, pp. 3342-3344 (1999).

[2] S. V. Milton, et al. "The FEL Development at the Advanced Photon Source," Proc. SPIE Int. Soc. Opt. Eng., pp. 86-95 (1999).

[3] K. Halbach, Lecture notes from APS seminar "Fundamental Properties of Magnetic Fields," July 1992.

[4] Opera 2D finite element code, Vector Fields Ltd., Oxford, England.

[5] ProlMechanica(R) 2000i ${ }^{2}$ design analysis code from PTC, Waltham, Mass. 